\title{
FATORES ORGANIZACIONAIS EM GESTÃO DE PORTFÓLIO DE PROJETOS: UMA PROPOSTA DE ESTRUTURA CONCEITUAL À LUZ DA LITERATURA
}

\author{
ORGANIZATIONAL FACTORS IN MANAGEMENT PORTFOLIO PROJECTS: A \\ PROPOSED CONCEPTUAL FRAMEWORK IN THE LIGHT OF THE LITERATURE
}

\section{Claudio Luis Carvalho Larieira}

Doutorando em Administração de Empresas pela Escola de Administração de Empresas de São Paulo da Fundação Getulio Vargas - EAESP/FGV

Coordenador de MBAs In Company da Escola de Administração de Empresas de São Paulo da Fundação Getúlio Vargas - EAESP/FGV

E-mail: claudio.larieira@fgv.br (Brasil)

\section{Alberto Luiz Albertin}

Doutor em Administração pela Universidade de São Paulo - USP

Professor da Escola de Administração de Empresas de São Paulo da Fundação Getulio Vargas EAESP/FGV

E-mail: albertin@fgv.br (Brasil) 


\title{
FATORES ORGANIZACIONAIS EM GESTÃO DE PORTFÓLIO DE PROJETOS: UMA PROPOSTA DE ESTRUTURA CONCEITUAL À LUZ DA LITERATURA
}

\begin{abstract}
RESUMO
Investimentos podem ser gerenciados sob a forma de portfólios com o objetivo de diminuir riscos, aumentar retornos e garantir maior efetividade dos investimentos. Algumas empresas procuram gerenciar seus investimentos usando a abordagem de projetos, criando assim a Gestão de Portfólio de Projetos (GPP). Além das questões técnicas ou metodológicas, outros fatores estão presentes neste processo, tais como o conhecimento e envolvimento das pessoas, a integração com outros processos da organização, as questões de âmbito político, o modelo de gestão adotado, a cultura organizacional, etc. Autores discutem a influência destes fatores organizacionais na GPP, porém o fazem de maneira pontual e fragmentada. Este artigo tem por objetivo investigar a partir da literatura quais são os fatores organizacionais que influenciam a GPP. É proposta uma estrutura que agrupa e consolida os fatores encontrados, o que permitirá às empresas identificar e entender quais fatores organizacionais influenciam a GPP e assim possam se preparar de maneira mais adequada para a implantação deste processo.
\end{abstract}

Palavras-chave: Projetos; Gestão de Portfólio de Projetos; Fatores Organizacionais.

\author{
ORGANIZATIONAL FACTORS IN MANAGEMENT PORTFOLIO PROJECTS: A \\ PROPOSED CONCEPTUAL FRAMEWORK IN THE LIGHT OF THE LITERATURE
}

\begin{abstract}
Investments can be managed as portfólios with the objective to reduce the risks, increase the returns and ensure greater effectiveness of investments. Some companies sought to manage their investments using the projects approach, creating thus the Project Portfólio Management (PPM). In addition to the technical or methodological issues, other factors are present in this process such as the professional's knowledge and involvement, integration with other processes in the organization, political issues, management model adopted, organizational culture, etc. Authors discuss the influence of these organizational factors in PPM, however they do so in a timely manner and fragmented. This article is aimed at investigating from the literature which is the organizational factors that influence the PPM. It is proposed a structure that combines and consolidates the factors found, which will allow companies to identify and understand which organizational factors influence the PPM and thus to prepare themselves for more adequately for the deployment of this process.
\end{abstract}

Keywords: Projects; Project Portfólio Management; Organizational Factors.

Revista de Gestão e Projetos - GeP, São Paulo, v. 4, n. 2, p 01-26, mai./ago. 2013. 


\section{INTRODUÇÃO}

Realizar um investimento envolve intrinsecamente os fatores de risco e retorno. Os investimentos podem ser gerenciados sob a forma de portfólios com o objetivo de diminuir os riscos, aumentar os retornos e garantir uma maior efetividade (Markowitz, 1959).

A partir da proposição seminal de Markowitz sobre análise de portfólios, outros autores procuraram responder à necessidade de gerenciar os investimentos das empresas em novos produtos, serviços, processos internos, sistemas ou estrutura organizacional (entre outros) usando para tanto a abordagem de projetos, criando o que hoje se denomina de Gestão de Portfólio de Projetos (a partir daqui apenas referenciada como GPP) (Meredith \& Mantel, 1985) (Wheelwright \& Clark, 1993) (Cooper, Edgett, \& Kleinschimidt, 2000) (Archer \& Ghasemzadeh, 1999) (PMI, 2008b).

À semelhança de outros processos executados nas organizações, a GPP é um conjunto de atividades inter-relacionadas que emprega técnicas e ferramentas para o atingimento de um objetivo específico. Além das questões meramente técnicas ou metodológicas de um processo, vários outros fatores estão presentes na execução deste processo ou concorrem para o sucesso dele, tais como o (i) conhecimento e envolvimento das pessoas, (ii) a atuação das partes interessadas do processo, (iii) a integração com outros processos da organização, (iv) questões políticas, (v) o modelo de gestão adotado, (vi) as políticas organizacionais estabelecidas, (vii) a cultura organizacional e (viii) a estrutura organizacional.

Alguns autores discutem de maneira direta ou indireta a presença e influência destes fatores organizacionais na GPP (McFarlan, McKenney, \& Pyburn, 1983) (Englund \& Graham, 1999) (Cooper, Edgett, \& Kleinschimidt, 2000) (Engwall \& Jerbrant, 2003) (Jeffery \& Leliveld, 2004) (Dooley, Lupton, \& O’Sullivan, 2005) (Pennypacker, 2005) (Rabechini, Maximiano, \& Martins, 2005) (Blomquist \& Muller, 2006) (Jayme, Perrone, Monteiro, Torres, \& Eichmann, 2006) (Martinsuo \& Lehtonen, 2007) (Christiansen \& Varnes, 2008) (Mariano, 2008) (Barros \& Mello, 2009) (Moeckel \& Forcellini, 2009) (Guedes et al, 2011) (Carneiro \& Martens, 2012), mas o fazem sobre fatores específicos, de maneira pontual e fragmentada, sem a consolidação dos fatores em sua abrangência e, consequentemente, sem uma visão holística.

Assim, este artigo tem como pergunta de pesquisa a seguinte questão: Quais são os fatores organizacionais que influenciam a gestão de portfólio de projetos à luz da literatura corrente sobre projetos?

Este artigo tem por objetivo apresentar uma proposta de estrutura conceitual que agrupe e

Revista de Gestão e Projetos - GeP, São Paulo, v. 4, n. 2, p 01-26, mai./ago. 2013. 
consolide os fatores organizacionais que influenciam a GPP. Esta estrutura permitirá às empresas e seus gestores identificarem e entender quais fatores organizacionais influenciam direta ou indiretamente a GPP e assim possam se preparar de maneira mais adequada para a adoção e implantação deste processo em suas organizações.

A GPP é um tema emergente em termos de prática organizacional e, portanto, desperta grande interesse das organizações e profissionais envolvidos na gestão de projetos (Fernandes, Silva, \& Turrioni, 2010). Em pesquisa realizada com 54 (cinquenta e quatro) executivos seniores de projetos sobre a adoção de boas práticas de GPP nos Estados Unidos (Pennypacker, 2005), foi evidenciado que mais de $90 \%$ das empresas possuíam baixa maturidade neste processo. De fato, a GPP tem se consolidado como uma disciplina organizacional apenas na última década (Killen, Hunt, \& Kleinschmidt, 2008).

\section{FUNDAMENTOS}

Esta seção apresentará os fundamentos que servem de base conceitual para este artigo. Inicialmente são apresentados os conceitos sobre projetos e gestão de projetos, em seguida é apresentada a definição de portfólio e gestão de portfólio (à luz do conceito seminal proposto por Markowitz) e, por último, a gestão de portfólio de projetos (GPP).

\subsection{SOBRE PROJETOS}

Um projeto pode ser definido como um empreendimento multidisciplinar e temporário que é executado segundo um ciclo de vida previamente definido e que tem como objetivo criar algum produto, serviço, conhecimento ou resultado que seja único, sendo utilizado para tanto recursos financeiros, humanos e materiais finitos (Martin, 1976) (Pinto \& Slevin, 1988) (Harrison, 1992) (Cleland \& Ireland, 2002) (PMI, 2008a).

Um projeto é também um empreendimento específico, exclusivo, dado o fato de que seus objetivos e resultados são específicos e suas entregas são singulares, sendo irrelevante saber se o projeto é pequeno ou grande em termos de escopo, curto ou longo em termos de prazo, pois o que mais importa é sua característica de ser único em termos de ação (Martin, 1976) (Meredith \& Mantel, 1985) (Pinto \& Slevin, 1988) (Harrison, 1992).

Esta característica da unicidade (ou não repetitividade) de um projeto é de fundamental

Revista de Gestão e Projetos - GeP, São Paulo, v. 4, n. 2, p 01-26, mai./ago. 2013. 
importância, pois é o que diferencia um projeto de uma operação, que é repetitiva e rotineira (Martin, 1976) (Meredith \& Mantel, 1985) (Harrison, 1992) (PMI, 2008a) (Dinsmore \& CabanisBrewin, 2009).

O sucesso de um projeto, de maneira geral, é avaliado pelo grau de atendimento do projeto aos requisitos técnicos e do cumprimento de prazo e custo estabelecidos. Porém, esta afirmação pode ser enganosa se for considerado que por vezes um projeto termina no prazo e no custo, entregando o que foi prometido em termos de escopo técnico, mas não necessariamente satisfaz aos demandantes e envolvidos. Neste sentido, ainda que prazo, custo e desempenho sejam importantes nesta avaliação, um fator adicional a ser considerado para explicitar o sucesso de um projeto é a satisfação das partes envolvidas (Harrison, 1992) (Pinto \& Slevin, 1988).

\subsection{SOBRE GESTÃO DE PROJETOS}

A gestão de projeto é um processo disciplinado e que tem por propósito geral garantir que os objetivos definidos para um projeto sejam plenamente atingidos, respeitando os custos, o prazo e o desempenho requerido, e isto se realiza através do envolvimento de pessoas em atividades de organização, planejamento e controle das atividades e dos recursos alocados ao projeto (Martin, 1976) (Meredith \& Mantel, 1985) (Harrison, 1992) (Kerzner, 2006).

Gerenciar projetos de uma forma estruturada e disciplinada permite com que sejam identificados e tratados com antecedência potenciais riscos, evitando que haja um dispêndio desnecessário de tempo e recursos. De fato, a gestão de projetos é uma abordagem diferenciada em relação às práticas de gestão tradicionalmente empregadas pela administração para gerenciar operações, pois tem como objeto de estudo e foco uma unidade de trabalho específica (neste caso, os projetos), o que requer formas especializadas de organização das atividades, de sistemas de informação, de profissionais qualificados em planejamento, finanças, controles e tratamento de problemas de relacionamento humano (Martin, 1976) (Harrison, 1992) (Cleland \& Ireland, 2002).

Sob a abordagem de gestão de projetos, um projeto tipicamente é dividido em fases, tarefas ou atividades (ou alguma outra forma de divisão do trabalho) para garantir que os objetivos sejam de fato cumpridos (Meredith \& Mantel, 1985) (Cleland \& Ireland, 2002) (PMI, 2008a). Ao término de cada fase é esperado que sejam disponibilizados os "entregáveis" (ou deliverables) parciais do projeto, que representam os produtos, bens, serviços, processos, estruturas organizacionais, políticas ou conhecimentos que traduzem de forma tangível os resultados do projeto (Meredith \& Mantel, 1985) (PMI, 2008a).

Revista de Gestão e Projetos - GeP, São Paulo, v. 4, n. 2, p 01-26, mai./ago. 2013. 
Basicamente, 5 (cinco) fatores fizeram com que a gestão de projetos emergisse no seio das organizações e se tornasse uma prática corrente (Meredith \& Mantel, 1985): (i) a necessidade de criar bens e serviços com alta complexidade, sofisticação e customização; (ii) a expansão exponencial do conhecimento humano; (iii) a intensa competição na qual as empresas se viram inseridas por conta do modelo econômico baseado no capitalismo; (iv) a crença ou senso comum das pessoas de que a tecnologia pode resolver os mais diversos problemas; (v) a abrangência e tamanho das ações a serem empreendidas pelas organizações, que crescem cada vez mais.

\subsection{SOBRE PORTFÓLIOS E GESTÃO DE PORTFÓLIO}

O conceito seminal que deu origem à abordagem de gestão de portfólio de projetos foi proposto inicialmente por Harry Markowitz, em 1959, como fruto de seu trabalho de pesquisa para a obtenção de seu titulo de Doutor e foi denominado por ele como Análise de Portfólio.

Quando se pretende realizar investimentos em ativos financeiros como ações de empresas, depósitos bancários (como CDB), fundos de renda fixa, poupança ou outros tipos de investimentos, faz-se necessário avaliar quais são as melhores opções de investimento, de maneira comparativa, sob a perspectiva do investidor. Em linhas gerais, a Análise de Portfólio tem por objetivo garantir a criação de um portfólio de investimentos com o melhor grau de eficiência possível (Markowitz, 1959).

Há fundamentalmente 2 (duas) características ou elementos em investimento que determinam a eficiência de um portfólio: (i) a incerteza sobre o retorno de um determinado ativo; (ii) a correlação existente entre os retornos dos ativos individuais. Um retorno representa tipicamente os ganhos de capital e os dividendos que um investidor percebe ou ganha ao final de um período de aplicação de seu capital em um dado investimento (Markowitz, 1959).

Mais do que uma lista de ações e títulos de boa qualidade, um bom portfólio pode ser entendido como uma carteira balanceada de investimentos que traz ao investidor proteção a seus investimentos e oportunidades com respeito a um amplo conjunto de contingências, de acordo com suas preferências e necessidades (Markowitz, 1959). Neste sentido, a Análise de Portfólio provê técnicas e ferramentas que ajudem os investidores a construir portfólios com o maior grau de eficiência possível, usando para tanto conceitos da matemática e estatística.

A Análise de Portfólio se inicia com a identificação e análise individual dos vários investimentos possíveis e termina com a criação de um portfólio integrado de investimentos, sob uma visão holística dos investimentos (Markowitz, 1959).

Revista de Gestão e Projetos - GeP, São Paulo, v. 4, n. 2, p 01-26, mai./ago. 2013. 
A predição sobre os retornos a serem obtidos com um determinado investimento é uma tarefa complexa dado que um investimento normalmente é suscetível a vários fatores externos (como mudanças em tensões entre países, cenário econômico, perspectiva de vida das pessoas, novas invenções, novas legislações, etc.) cujo controle não está ao alcance dos investidores ou dos analistas de ativos. Neste sentido, em todo investimento realizado há sempre um componente intrínseco de incerteza sobre seu retorno (Markowitz, 1959).

\subsection{SOBRE GESTÃO DE PORTFÓLIO DE PROJETOS}

O ponto de partida para o entendimento sobre a GPP se dá a partir da atividade de seleção de projetos. Uma das áreas de conhecimento que mais contribuiu para a criação de teorias e métodos para a seleção de projetos foi à área de $\mathrm{P} \& \mathrm{D}$ dada a necessidade das empresas estabelecerem processos para o lançamento de produtos cada vez mais baratos, com alta qualidade e de maneira mais rápida a partir dos meados da década de 1980 (Meredith \& Mantel, 1985) (Wheelwright \& Clark, 1993) (Killen, Hunt, \& Kleinschmidt, 2008).

Segundo Meredith \& Mantel (1985), “a avaliação e seleção de projetos é o processo de avaliar projetos individuais ou grupos de projetos e então escolher destes quais serão implementados de forma que os objetivos estratégicos da organização sejam atingidos".

A seleção de projetos não é uma atividade de execução única no ciclo de vida de gestão de um portfólio. Pelo contrario, dado que as variáveis internas e externas ao portfólio podem sofrer alterações ao longo do ciclo de vida de execução de um portfólio, de tempos em tempos é necessário que sejam avaliados os critérios de seleção dos projetos a ponto de um projeto ser descontinuado para que outro possa fazer ser incorporado à carteira de projetos e assim garantir a qualidade do portfólio (Archer \& Ghasemzadeh, 1999) (Cooper, Edgett, \& Kleinschimidt, 2000).

A seleção de projetos é um passo importante na criação de portfólio de projetos, mas há que se diferenciar a seleção de projetos do processo de GPP. Enquanto a seleção de projetos tem por objetivo avaliar um projeto individualmente (segundo critérios pré-estabelecidos) e determinar se este projeto representa um bom investimento para uma companhia, a GPP refere-se a um processo dinâmico e integrado que tem por objetivo avaliar a viabilidade e alinhamento estratégico de vários projetos ao mesmo tempo, em um formato de portfólio de projetos, sendo para tanto avaliados, selecionados e priorizados novos projetos enquanto outros projetos correntes podem ser acelerados, cancelados ou despriorizados (Cooper, Edgett, \& Kleinschimidt, 2000) (Ghasemzadeh; Archer, 2000) (Kerzner, 2006).

Revista de Gestão e Projetos - GeP, São Paulo, v. 4, n. 2, p 01-26, mai./ago. 2013. 
Uma definição importante neste ponto diz respeito ao conceito de portfólio, tratado agora especificamente para o tema de projetos. Um portfólio de projetos é um grupo de projetos submetidos ao patrocínio de uma organização em particular e que disputam recursos entre si dentro do portfólio (Archer \& Ghasemzadeh, 1999). Segundo o PMI (2008b), um portfólio é uma coleção de projetos e/ou programas e outros trabalhos que são agrupados para facilitar a efetiva gestão para que sejam atingidos os objetivos estratégicos. Os componentes de um portfólio devem ser quantificáveis, ou seja, devem possuir atributos que permitam aos gestores de um portfólio de projetos mensurá-los, classificá-los e priorizá-los sempre que necessário. Não é obrigatório que os componentes do portfólio (ou projetos) sejam interdependentes ou diretamente relacionados, mas é importante que um portfólio reflita uma visão de investimentos em um dado momento.

Neste sentido, a GPP pode ser vista como uma evolução natural da atividade de seleção de projetos e representa um processo mais holístico e integrado (considerando conhecimentos, perfis, ferramentas e técnicas), sendo composto por vários estágios de decisão e tendo como objetivo criar e gerenciar de maneira centralizada portfólios de projetos alinhados às diretrizes estratégicas estabelecidas por uma organização à luz de suas restrições financeiras, de tecnologia, de tempo e de recursos humanos (Ghasemzadeh; Archer, 2000) (Pennypacker, 2005) (PMI, 2008b).

É importante também que seja denotada a diferença que existe entre a GPP e a gestão de projetos: enquanto nesta última o objetivo é garantir que o projeto seja executado da maneira correta ("doing projects right"), o objetivo da GPP é executar os projetos corretos ("doing the right projects") (Cooper, Edgett, \& Kleinschimidt, 2000) (Pennypacker, 2005) (PMI, 2008b). Em outros termos, a GPP é um mecanismo que auxilia as empresas a escolher os melhores projetos ao ponto em que a gestão de projetos auxilia as empresas a entregar seus projetos dentro do escopo, prazo e custos estabelecidos.

Várias evoluções e melhorias foram sendo propostas pelos autores ao processo de GPP no decorrer do tempo e atualmente este processo pode ser composto das seguintes atividades:

- Estabelecimento de Estrutura organizacional - criação e estabelecimento de comitês de trabalho na organização com o objetivo de executar e monitorar as atividades do processo; estes comitês podem ser formados por membros da alta direção, gerentes funcionais, gerentes dos projetos e clientes internos para garantir legitimidade e representatividade das decisões (Englund \& Graham, 1999) (Artto \& Dietrich, 2007);

Revista de Gestão e Projetos - GeP, São Paulo, v. 4, n. 2, p 01-26, mai./ago. 2013. 
- Identificação de potenciais projetos (ou inventário de componentes) - levantamento dos projetos correntes, dos projetos propostos e dos projetos que estão no aguardo de aprovação; devem ser descritas as informações sobre os projetos tais como prazos, custos, orçamentos, dependências, iniciativas estratégicas, benefícios esperados, riscos, prioridade relativa, valor e recursos necessários (Englund \& Graham, 1999) (Pennypacker, 2005) (Kerzner, 2006) (PMI, 2008b);

- Categorização de projetos - com o objetivo de classificar os projetos em grupos afins e assim suportar o processo de tomada de decisão através da comparação de projetos que possuam semelhanças; a categorização ajuda também a organização a identificar se há categorias de projetos com falta ou excesso de projetos à luz de seus objetivos estratégicos (Englund \& Graham, 1999) (Artto \& Dietrich, 2007) (PMI, 2008b);

- Criação de critérios de avaliação dos projetos - para cada categoria de projetos, são necessários que sejam identificados e claramente descritos os critérios que farão parte do modelo de seleção e priorização dos projetos, estabelecendo assim atributos de avaliação e comparação entre os projetos; quanto mais objetivos forem estes critérios, mais assertivas serão as atividades de seleção e priorização dos projetos; pesos relativos podem ser atribuídos a cada critério estabelecido para diferenciar a importância dos critérios dentro do modelo proposto (Meredith \& Mantel, 1985) (Englund \& Graham, 1999) (Kerzner, 2006) (Artto \& Dietrich, 2007) (PMI, 2008b);

- Avaliação dos projetos - aplicação dos critérios de avaliação a cada projeto, resultando em uma lista de projetos devidamente "escorados", em uma forma de ranking (Englund \& Graham, 1999) (Pennypacker, 2005) (Kerzner, 2006) (PMI, 2008b);

- Levantamento de capacidade e recursos de organização - para suportar o processo de seleção de projetos o sentido de quantos projetos podem ser executados dentro do portfólio, é necessário que a organização previamente identifique a capacidade disponível que tem rem relação a recursos humanos, físicos e financeiros, o que ajudará a estimar o ponto de corte dos projetos a serem selecionados e priorizados (Englund \& Graham, 1999); 
- Seleção dos projetos - com base na lista de projetos identificados, categorizados, avaliados e classificados em termos de pontuação (score) e na capacidade da organização em executar os projetos, esta atividade tem por objetivo recomendar quais projetos deverão ser selecionados para compor o portfólio (Englund \& Graham, 1999) (Pennypacker, 2005) (Kerzner, 2006) (PMI, 2008b); estar nesta lista não significa necessariamente que o projeto será selecionado, uma vez que ainda há a atividade de balanceamento de projetos que pode alterar a lista de projetos a serem de fato selecionados;

- Priorização dos projetos - nesta atividade, os projetos recomendados para seleção são priorizados para serem executados no portfólio de acordo com as diretrizes ou urgências impostas pela organização, sendo também levado em conta as dependências existentes entre os projetos em termos de precedência e sucessão (Englund \& Graham, 1999) (Pennypacker, 2005) (Kerzner, 2006) (PMI, 2008b);

- Balanceamento do portfólio de projetos - com o objetivo de obter o melhor mix de projetos dentro do portfólio criado, esta atividade permite com que os tomadores de decisão sobre o portfólio possam incluir novos projetos, excluir projetos existentes e assim alterar a composição de um portfólio; esta ação está baseada na premissa de que os modelos matemáticos ou de scoragem possam não estar completamente adequados às diretrizes estratégicas, bem como nem sempre consiga traduzir as demandas pessoais dos gestores; ainda que seja uma atividade possível, deve-se tomar o cuidado de não retirar a legitimidade das decisões tomadas pelos executivos em tempo de seleção e priorização dos projetos, sob pena de desestabilizar o processo de GPP na organização (Englund \& Graham, 1999) (PMI, 2008b);

- Autorização - esta atividade formalmente aloca os recursos financeiros e humanos requeridos para a execução dos projetos do portfólio, representando assim um marco de início do portfólio na organização junto às partes interessadas (PMI, 2008b);

- Monitoramento e controle - métricas são capturadas para avaliar o desempenho de cada projeto dentro do portfólio, podendo alguns projetos ser descontinuados caso não 
estejam mais aderentes aos objetivos do portfólio bem como novos projetos serem incorporados ao portfólio (Pennypacker, 2005); são exemplos de métricas de um portfólio de projetos (PMI, 2008b): atingimento de metas, contribuição financeira, desenvolvimento e manutenção de ativos, satisfação do usuário, perfil do risco, capacidade dos recursos, ROI, valor presente líquido, entre outros;

- Reporte e revisão - deve haver uma adequada comunicação aos interessados em um portfólio de projetos (a saber, os gerentes de projetos e programas, os gerentes do portfólio, o patrocinador do portfólio, bem como as partes interessadas neste portfólio, especificamente) sobre o conteúdo do portfólio e os resultados obtidos a cada período de tempo (Artto \& Dietrich, 2007) (PMI, 2008b); as revisões de portfólio têm por objetivo garantir que o portfólio de projetos continue aderente aos objetivos para o qual foi criado, sendo possível que projetos sejam descontinuados por não estarem mais aderentes ao portfólio e projetos sejam incorporados para garantir o atingimento dos objetivos do portfólio (Cooper, Edgett, \& Kleinschimidt, 2001) (Artto \& Dietrich, 2007);

- Replanejamento ou Mudança Estratégica - por vezes, as premissas consideradas para a criação de um portfólio mudam ou mesmo o cenário econômico externo ou o ambiente organizacional interno sofrem alterações, sendo requerido que o portfólio seja replanejado caso haja grandes mudanças estratégicas a serem implementadas; neste momento, os líderes e gestores devem avaliar o impacto das mudanças percebidas e replanejar o portfólio para garantir o sucesso da organização a partir de seus projetos (Pennypacker, 2005) (PMI, 2008b).

\section{METODOLOGIA}

Esta pesquisa foi realizada segundo a abordagem qualitativa e possui um caráter exploratório. Foi utilizada a técnica de análise de texto para a identificação, comparação e classificação dos termos e palavras que representam os fatores organizacionais da GPP nos trabalhos avaliados.

A coleta de dados para a realização desta pesquisa foi realizada entre os meses de Setembro

Revista de Gestão e Projetos - GeP, São Paulo, v. 4, n. 2, p 01-26, mai./ago. 2013. 
de 2010 a Março de 2011 em sites de busca (como Jstore, Ebsco e Google Acadêmico) e no catálogo virtual da biblioteca da Fundação Getulio Vargas, em São Paulo. Foi utilizada a palavrachave "portfólio de projeto" nas línguas portuguesa, inglesa e espanhola, não sendo limitada a busca em termos de período das publicações ou classificações de periódicos (Qualis). O critério utilizado para a seleção dos trabalhos foi a ocorrência das palavras-chave no título e/ou no resumo dos artigos.

Após a busca inicial pela palavra-chave, realizou-se um trabalho de consulta aos periódicos encontrados na amostra inicial utilizando-se novamente a palavra-chave, acrescidos neste momento dos autores e eventos identificados, sendo o mesmo trabalho realizado nas bases de dados das escolas e instituições identificadas para a busca de dissertações e teses. Por ultimo, foram analisadas as referencias bibliográficas de todos os trabalhos até então encontrados como uma forma de identificação de mais títulos para a amostra. Como resultado final das buscas, foram encontrados 392 títulos (entre artigos, livros, dissertações e teses), dos quais 20 foram retirados da amostra por não possuírem informações adequadas ao trabalho de análise.

Para a consolidação dos dados das publicações foi criada uma planilha em formato MSExcel, contendo as seguintes informações: (i) tipo de publicação, (ii) relação direta com gestão de portfólio de projetos; (iii) título, (iv) ano de publicação, (v) periódico/instituição, (vi) país de publicação, (vii) nível de análise, (viii) método de pesquisa, (ix) abordagem de pesquisa, (x) segmento de negócio, (xi) sub-processo de gestão de portfólio de projeto, (xii) aspecto abordado, (xiii) nome do autor/coautor, (xiv) palavras-chave e (xv) teorias citadas. Os dados dos trabalhos foram examinados através de uma primeira análise diagonal (para extração das principais informações) e posteriormente através de uma análise mais profunda (para a identificação dos fatores organizacionais).

\section{ANÁLISE E DISCUSSÃO DOS RESULTADOS}

Para a identificação dos fatores organizacionais que influenciam a GPP, foram utilizados artigos e trabalhos acadêmicos que citam de maneira direta ou indireta estes fatores quando da adoção e execução do processo ora analisado. Foram considerados para esta atividade de revisão bibliográfica todos os trabalhos que abordam GPP independente do segmento de negócio para o qual foi escrito, o que garantirá maior chance de se encontrar os fatores organizacionais.

Conforme apresentado na introdução deste trabalho, são considerados fatores 
organizacionais da GPP os elementos presentes nas organizações e que fazem parte de seu cenário de negócio ou de sua dinâmica de operação e desta maneira servem de suporte ou "pano de fundo" ao processo de GPP.

Em ordem cronológica de publicação dos trabalhos, são apresentados a seguir os fatores organizacionais e suas respectivas descrições, segundo seus autores. Como alguns fatores organizacionais se repetem entre os autores, a cada novo autor citado serão apresentados apenas os fatores inéditos na sequência do texto. Ao final desta seção, estes fatores organizacionais são consolidados em um quadro com todos os respectivos autores.

McFarlan, McKenney, \& Pyburn (1983) ao tratar de planejamento de sistemas de informação identificaram alguns fatores organizacionais que podem ser, por analogia, atribuídos também a GPP:

- A estabilidade do ambiente organizacional em relação à gestão também pode influenciar o planejamento dos sistemas de informações (quanto mais instável for o ambiente, menor será a probabilidade de se ter um planejamento adequado), o que leva a inferir que Estabilidade da Gestão é um fator organizacional que deve ser considerado para a GPP;

- Por conta de suas culturas, organizações podem adotar estilos de comunicação mais formais ou menos formais quando gerenciam seus negócios e projetos, o que implicitamente se transfere ao processo de GPP; assim, o Grau de Formalidade empregado na comunicação e na execução dos processos pode ser considerado um fator organizacional da GPP;

- Quanto maior o tamanho e a complexidade de uma organização, maior será a necessidade de processos e sistemas de informação; o Porte da Organização pode então ser um fator organizacional que influenciará a GPP, demandando um processo mais formal.

A partir de um estudo de caso realizado na HP (Hewlett-Packard) sobre a adoção de GPP, Englund \& Graham (1999) recomendaram que se atentasse aos seguintes pontos:

Revista de Gestão e Projetos - GeP, São Paulo, v. 4, n. 2, p 01-26, mai./ago. 2013. 
- O estabelecimento de comitês de seleção de projetos e a participação de membros da alta gestão são importantes fatores críticos de sucesso para a adoção de GPP, pois garante que a alta gestão e os gerentes de projeto compartilhem de uma mesma visão em termos de estratégia e projetos; o fator organizacional que traduz estas necessidades pode ser denominado de Visão Compartilhada;

- As organizações tipicamente definem e tornam explícitos sua visão, missão, crenças, valores e objetivos estratégicos, estas informações servem de insumo para o Alinhamento Estratégico entre os projetos e a estratégia da organização;

- As informações sobre os projetos que estão sendo avaliados na GPP é outro fator organizacional citado por estes autores quando alertam sobre a necessidade de se avaliar a qualidade dos dados obtidos bem como a eficiência das técnicas de coleta destes dados; Qualidade das Informações dos Projetos é o termo que será usado para definir esta necessidade;

- Além de informações sobre os projetos em análise, é necessário que se tenha uma boa base de dados contendo as informações dos projetos passados; isto permitirá que se realizem estimativas e simulações confiáveis para definir prazos e recursos para os novos projetos, o que neste trabalho se definirá como Qualidade dos Dados

\section{Históricos;}

- É importante que as organizações efetuem um levantamento prévio e minucioso para identificar os recursos disponíveis para o desenvolvimento dos projetos, o que será denominado como a Disponibilidade de Recursos;

- Para que a GPP seja implementada com sucesso em uma organização, é recomendado que uma unidade organizacional ou uma área seja criada com o objetivo de executar ou dar suporte a este processo, sendo aqui identificado o fator organizacional denominado de Suporte Organizacional;

- Além do suporte dado por uma área, por vezes faz-se necessário "evangelizar" as 
demais áreas da organização e seus gestores sobre a importância e benefícios da GPP, tendo como finalidade obter o Engajamento dos Participantes no processo e, consequentemente, o comprometimento deles;

- Ferramentas de Apoio (sistemas ou aplicações de software) devem suportar o processo de GPP para garantir o tratamento e o registro adequado das informações dos projetos e dos resultados do processo;

- Por se tratar de um processo que envolve decisões sobre investimentos em projetos (e consequentemente pode afetar interesses de áreas e gestores na organização), a GPP possui um viés altamente politico, o que pode causar em algum momento Resistência das Pessoas em relação à sua adoção.

Cooper, Edgett, \& Kleinschimidt (2000) realizaram importante investigação empírica sobre o uso da GPP em empresas e identificaram os seguintes pontos críticos na adoção deste processo:

- Não é tarefa simples realizar o balanceamento dos recursos uma vez que os projetos tipicamente demandam em tempo de execução recursos extras além do planejado, bem como os gestores tem dificuldade em conseguir equilíbrio entre os recursos demandados pelos projetos e recursos disponíveis; esta é uma variação do fator organizacional identificado anteriormente como Disponibilidade de Recursos, mas que remete de fato ao problema do Compartilhamento dos Recursos;

- Os gestores tem dificuldade em definir os projetos que devem ser selecionados, mantidos ou eliminados, e isto ocorre em grande parte por conta da baixa Qualidade das Informações sobre o Negócio, por vezes ainda incipientes em tempo de seleção e priorização dos projetos;

- Uma organização pode ter em seu portfólio muitos projetos pequenos e com pouca contribuição percebida, o que dificulta a execução da GPP por conta do volume de informações a serem processadas e do grande esforço necessário para avalia-los, selecioná-los e priorizá-los; neste sentido a Granularidade dos Projetos pode ser um fator organizacional a ser considerado para a GPP.

Revista de Gestão e Projetos - GeP, São Paulo, v. 4, n. 2, p 01-26, mai./ago. 2013. 
Subjacente ao fator organizacional de Compartilhamento dos Recursos, segundo Engwall \& Jerbrant (2003) a Competição entre os Projetos pode estar presente na GPP visto que algumas organizações de maneira deliberada ou intuitiva incorporam em sua cultura esta prática, o que potencializa o problema da "Síndrome de Alocação de Recursos", termo por eles cunhado. Ainda segundo Engwall \& Jerbrant (2003), há empresas que estão mais focadas em resolver problemas de curto prazo da operação ao invés de darem prioridade a ações de longo prazo, tendo como consequência a perda de foco do portfólio de projetos. Este fator organizacional pode ser definido como o Conflito Operações X Projetos.

Jeffery \& Leliveld (2004) realizaram um estudo para identificar a maturidade das organizações na GPP em TI e seus respectivos componentes, sendo desdobrados deste estudo alguns fatores organizacionais que estão presentes no processo de GPP, sendo eles:

- Não é incomum que em uma organização uma ou várias áreas façam a seleção e priorização de projetos sem considerar que estes projetos podem também estar na pauta de outras áreas; ou seja, a falta de Integração entre as Áreas de uma organização durante a execução da GPP pode fazer com que sejam desenvolvidos projetos em duplicidade ou com escopos semelhantes;

- Os profissionais envolvidos na GPP devem possuir conhecimento básico sobre as atividades e as técnicas a serem empregadas neste processo, sendo identificado o fator organizacional ora denominado Conhecimento sobre GPP;

- Algumas organizações executam a GPP, porém sem uma formalização do processo em termos de fluxo, atividades, alçadas, políticas e regras, o que pode gerar entendimentos ambíguos dos participantes; outras por sua vez, possuem processos de GPP definidos, gerenciados e controlados; o nível de Maturidade da GPP é um fator organizacional que pode influenciar na execução da GPP.

Dooley, Lupton, \& O’Sullivan (2005) discutem a gestão de projetos múltiplos como uma necessidade competitiva moderna nas organizações e abordam alguns fatores organizacionais que podem influenciar a GPP:

Revista de Gestão e Projetos - GeP, São Paulo, v. 4, n. 2, p 01-26, mai./ago. 2013. 
- Executar o processo de GPP implica em que uma organização possua previamente institucionalizados os processos de gestão de projetos, sob pena de não haver informações suficientes e de qualidade sobre os projetos e seus resultados para alimentar a GPP; por conseguinte, o nível de Maturidade da GP é um fator organizacional;

- Ainda que sejam estabelecidos comitês de seleção e priorização de projetos com participação de membros da alta gestão, é imprescindível que haja Apoio da Liderança para garantir que o processo tenha um suporte politico na organização e não venha a sofrer boicotes pelos gerentes táticos e operacionais durante sua execução e acompanhamento;

- De maneira geral as empresas executam seus processos de GPP em períodos determinados do ano, tipicamente nos momentos de formulação de suas estratégias ou da elaboração dos orçamentos de suas áreas; como o processo de GPP é um processo cíclico e dinâmico, a Continuidade do Processo de GPP no tempo pode se configurar como um fator organizacional;

- Um processo de GPP requer comunicação constante, o que evita ou diminui a resistência das pessoas ao processo bem como aumenta o nível de engajamento no processo; o nível de Transparência do Processo se traduz no quanto a organização explicita ou não sobre as politicas, os critérios de decisão empregados e os resultados da GPP e tem relação com estes fatores anteriormente citados;

- A capacidade de uma organização em aprender com os erros e acertos em seus projetos do passado e a partir destas lições aprendidas tomar decisões mais acertadas a respeito de projetos futuros reflete a Aprendizagem Organizacional presente nesta organização.

Pennypacker (2005) argumenta que, para que a GPP tenha sucesso em uma organização, faz-se necessário estabelecer uma Governança do Processo de maneira que sejam claras e entendidas por todos os participantes as regras de como o processo será executado. Também como ocorre em outros processos, o estabelecimento de Papéis e Responsabilidades para o processo de

Revista de Gestão e Projetos - GeP, São Paulo, v. 4, n. 2, p 01-26, mai./ago. 2013. 
GPP ajudará com que o processo seja executado com sucesso (Blomquist \& Muller, 2006) (Pennypacker, 2005).

Quando uma organização seleciona projetos é natural que durante este processo venha à tona a sua disposição em tomar mais riscos ou menos riscos (Christiansen \& Varnes, 2008), o que pode ser traduzido pelos tipos de projeto que ela escolhe: se são projetos de ruptura ou de inovação (organizações arrojadas) ou se são projetos mais simples e com pouco risco (organizações conservadoras). Esta opção de "apetite" ao risco em relação aos projetos é uma característica que se forma na organização no decorrer de sua história e tem relação com suas crenças e valores e projetos passados, podendo ser definido como o fator organizacional de Disposição ao Risco.

O quadro abaixo consolida os fatores organizacionais encontrados nos trabalhos sobre GPP e as respectivas citações, segundo ordem alfabética:

\begin{tabular}{|c|l|}
\hline FATOR ORGANIZACIONAL & \multicolumn{1}{|c|}{ AUTORES } \\
\hline Alinhamento Estratégico & $\begin{array}{l}\text { McFarlan, McKenney, \& Pyburn, 1983 } \\
\text { Carneiro \& Martens, 2012 }\end{array}$ \\
\hline Apoio da Liderança & $\begin{array}{l}\text { Dooley, Lupton, \& O'Sullivan, 2005 } \\
\text { Jayme et al, 2006 }\end{array}$ \\
\hline Aprendizagem Organizacional & $\begin{array}{l}\text { Dooley, Lupton, \& O'Sullivan, 2005 } \\
\text { Christiansen \& Varnes, 2008 }\end{array}$ \\
\hline Compartilhamento dos Recursos & $\begin{array}{l}\text { Cooper, Edgett, \& Kleinschimidt, 2000 } \\
\text { Engwall \& Jerbrant, 2003 } \\
\text { Dooley, Lupton, \& O'Sullivan, 2005 } \\
\text { Pennypacker, 2005 } \\
\text { Barros \& Mello, 2009 }\end{array}$ \\
\hline Competição entre os Projetos & $\begin{array}{l}\text { Engwall \& Jerbrant, 2003 } \\
\text { Dooley, Lupton, \& O'Sullivan, 2005 }\end{array}$ \\
\hline Conflito Operações X Projetos & $\begin{array}{l}\text { Engwall \& Jerbrant, 2003 } \\
\text { Dooley, Lupton, \& O'Sullivan, 2005 } \\
\text { Christiansen \& Varnes, 2008 }\end{array}$ \\
\hline $\begin{array}{l}\text { Jaffery \& Leliveld, 2004 } \\
\text { Carneiro \& Martens, 2012 }\end{array}$ \\
\hline ayme al, 2006
\end{tabular}

Revista de Gestão e Projetos - GeP, São Paulo, v. 4, n. 2, p 01-26, mai./ago. 2013. 


\begin{tabular}{|c|c|}
\hline Continuidade do Processo & Dooley, Lupton, \& O’Sullivan, 2005 \\
\hline Disponibilidade de Recursos & $\begin{array}{l}\text { Englund \& Graham, } 1999 \\
\text { Dooley, Lupton, \& O’Sullivan, } 2005 \\
\text { Carneiro \& Martens, } 2012\end{array}$ \\
\hline Disposição ao Risco & Christiansen \& Varnes, 2008 \\
\hline Engajamento dos Participantes & $\begin{array}{l}\text { Englund \& Graham, } 1999 \\
\text { Jayme et al, } 2006\end{array}$ \\
\hline Estabilidade da Gestão & McFarlan, McKenney, \& Pyburn, 1983 \\
\hline Ferramentas de Apoio & Englund \& Graham, 1999 \\
\hline Governança do Processo & $\begin{array}{l}\text { Pennypacker, } 2005 \\
\text { Christiansen \& Varnes, } 2008\end{array}$ \\
\hline Granularidade dos Projetos & $\begin{array}{l}\text { Cooper, Edgett, \& Kleinschimidt, } 2000 \\
\text { Carneiro \& Martens, } 2012\end{array}$ \\
\hline Grau de Formalidade & $\begin{array}{l}\text { McFarlan, McKenney, \& Pyburn, } 1983 \\
\text { Dooley, Lupton, \& O’Sullivan, } 2005\end{array}$ \\
\hline Integração entre as Áreas & $\begin{array}{l}\text { Jeffery \& Leliveld, } 2004 \\
\text { Dooley, Lupton, \& O’Sullivan, } 2005\end{array}$ \\
\hline Maturidade da GP & $\begin{array}{l}\text { Dooley, Lupton, \& O’Sullivan, } 2005 \\
\text { Pennypacker, 2005 } \\
\text { Rabechini, Maximiano, \& Martins, } 2005 \\
\text { Martinsuo \& Lehtonen, } 2007 \\
\text { Guedes et al, } 2011\end{array}$ \\
\hline Maturidade da GPP & $\begin{array}{l}\text { Jeffery \& Leliveld, } 2004 \\
\text { Pennypacker, 2005 } \\
\text { Jayme et al, 2006 } \\
\text { Mariano, 2008 } \\
\text { Barros \& Mello, } 2009 \\
\text { Carneiro \& Martens, } 2012\end{array}$ \\
\hline Papéis e Responsabilidades & $\begin{array}{l}\text { Pennypacker, } 2005 \\
\text { Blomquist \& Muller, } 2006\end{array}$ \\
\hline Porte da Organização & McFarlan, McKenney, \& Pyburn, 1983 \\
\hline
\end{tabular}

Revista de Gestão e Projetos - GeP, São Paulo, v. 4, n. 2, p 01-26, mai./ago. 2013. 


\begin{tabular}{|c|l|}
\hline Qualidade das Informações dos Projetos & $\begin{array}{l}\text { Englund \& Graham, 1999 } \\
\text { Cooper, Edgett, \& Kleinschimidt, 2000 } \\
\text { Dooley, Lupton, \& O’Sullivan, 2005 } \\
\text { Pennypacker, 2005 } \\
\text { Martinsuo \& Lehtonen, 2007 } \\
\text { Moeckel \& Forcellini, 2009 } \\
\text { Carneiro \& Martens, 2012 }\end{array}$ \\
\hline Qualidade das Informações sobre o Negócio & $\begin{array}{l}\text { Cooper, Edgett, \& Kleinschimidt, 2000 } \\
\text { Moeckel \& Forcellini, 2009 }\end{array}$ \\
\hline Qualidade dos Dados Históricos & $\begin{array}{l}\text { Englund \& Graham, 1999 } \\
\text { Jeffery \& Leliveld, 2004 } \\
\text { Moeckel \& Forcellini, 2009 }\end{array}$ \\
\hline Resistência das Pessoas & Englund \& Graham, 1999 \\
\hline Suporte Organizacional & $\begin{array}{l}\text { Englund \& Graham, 1999 } \\
\text { Jeffery \& Leliveld, 2004 } \\
\text { Jayme et al, 2006 }\end{array}$ \\
\hline Transparência do Processo & $\begin{array}{l}\text { Dooley, Lupton, \& O’Sullivan, 2005 } \\
\text { Pennypacker, 2005 }\end{array}$ \\
\hline $\begin{array}{l}\text { Englund \& Graham, 1999 } \\
\text { Jeffery \& Leliveld, 2004 } \\
\text { Pennypacker, 2005 }\end{array}$ \\
\hline
\end{tabular}

Quadro 1 - Fatores organizacionais em GPP

Fonte: Elaborado pelos autores.

A partir da identificação dos fatores organizacionais citados direta ou indiretamente na literatura encontrada sobre GPP, foi realizado um trabalho de agrupamento destes fatores em torno de temas mais abrangentes, conforme as afinidades entre os fatores organizacionais, sendo gerados então os agrupamentos abaixo com suas respectivas descrições:

- Recursos - diz respeito a todos os recursos organizacionais (pessoas, infraestrutura, ferramentas, investimentos, etc.) necessários para a execução e gestão da GPP na organização;

- Informações - tem relação com as informações do negócio e dos projetos que serão utilizadas pelos participantes da GPP para a tomada de decisão em tempo de avaliação,

Revista de Gestão e Projetos - GeP, São Paulo, v. 4, n. 2, p 01-26, mai./ago. 2013. 
categorização, seleção, priorização e balanceamento dos projetos;

- Pessoas - este tema se refere às competências, habilidades e envolvimento dos vários participantes do processo de GPP;

- Organização - refletem as características intrínsecas a uma organização e que de certa maneira definem sua cultura e "modus operandi" ao executar seus processos organizacionais, consequentemente, transcendendo para a GPP;

- Processo - refere-se à definição e execução do processo de GPP na organização bem como sua integração com os demais processos vigentes da organização;

- Política - trata dos relacionamentos e acordos políticos (sejam estes tácitos ou explícitos, formais ou informais, individuais ou coletivos) que são firmados entre os participantes do processo;

- Estratégia - todas as decisões que direcionam a organização, seja em ações de longo, médio ou curto prazo, estão agrupadas em torno deste tema que serve de orientação e balizador da GPP;

- Gestão - estabelecidas as estratégias e os processos que viabilizarão a GPP, a gestão se encarrega de prover a organização, coordenação, gerenciamento e acompanhamento das práticas de GPP na organização.

A estrutura que consolida e representa os fatores organizacionais que influenciam a GPP (conforme proposto no objetivo deste artigo), se encontra abaixo apresentada:

Revista de Gestão e Projetos - GeP, São Paulo, v. 4, n. 2, p 01-26, mai./ago. 2013. 
Figura 2 - Fatores organizacionais que influenciam a GPP

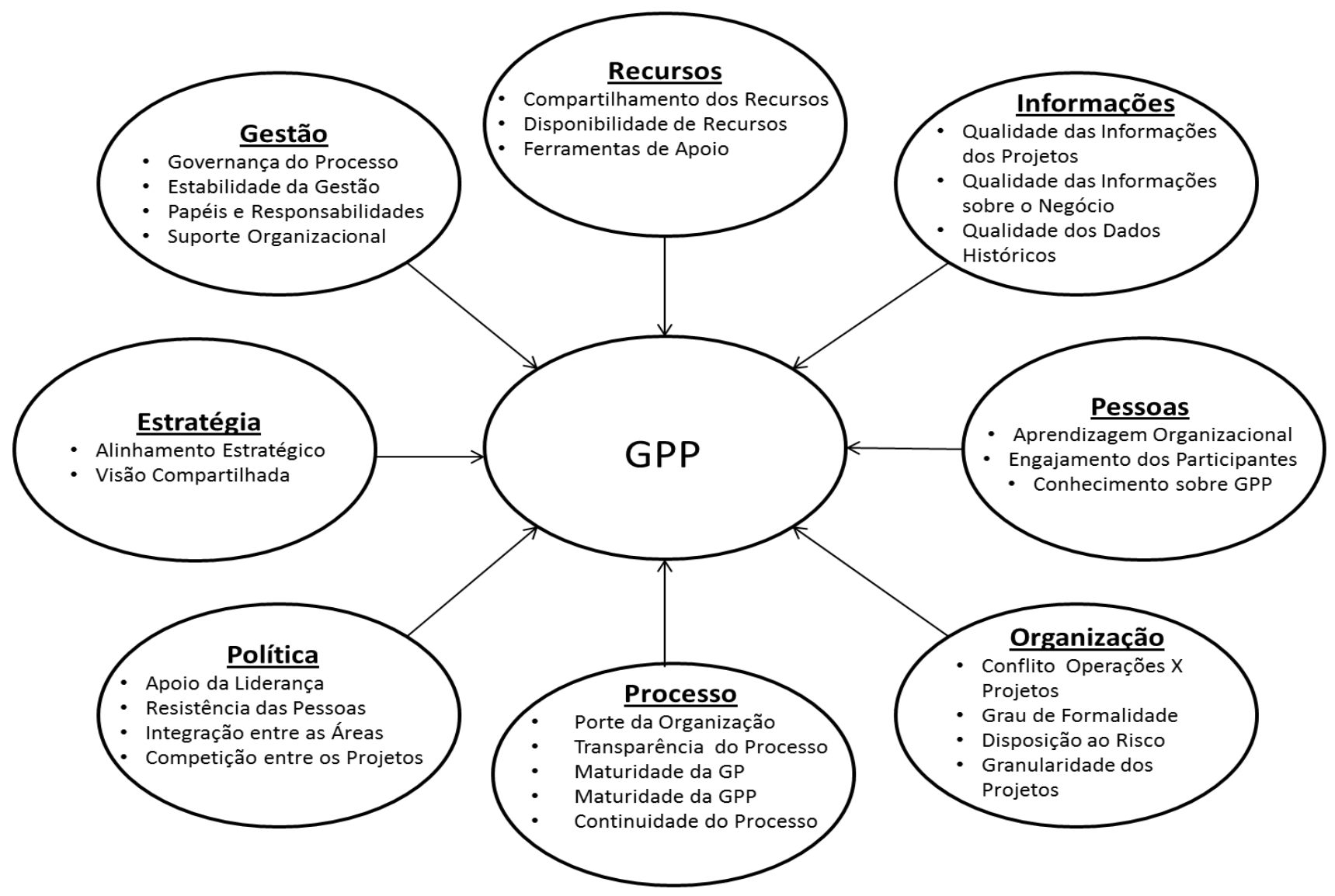

Fonte: Elaborado pelos autores.

\section{CONSIDERAÇÕES FINAIS}

A principal contribuição deste artigo se refere à criação de uma estrutura que permite representar os diversos fatores organizacionais que podem influenciar de maneira direta ou indireta o processo de GPP em uma organização. Dado que na literatura pesquisada não foram encontradas estruturas semelhantes à proposta neste artigo, pode-se afirmar que, além de inpedita, esta estrutura oferecerá respostas a uma lacuna de conhecimento até então abordada de maneira fragmenttada nos trabalhos sobre GPP.

Uma vez que a GPP não seja ainda um processo plenamente estabelecido e executado na maioria das organizações que desenvolvem projetos, esta estrutura permitirá aos lideres e gestores 
analisar e compreender com maior clareza os fatores organizacionais presentes e suas influências quando da avaliação, categorização, seleção, priorização e monitoramento de suas carteiras de projetos, não se limitando apenas às questões de cunho técnico ou metodológico.

Como este artigo é parte de uma pesquisa maior e mais detalhada que se encontra em andamento sobre a GPP, serão realizados estudos futuros como como continuidade deste artigo. Um primeiro estudo a ser realizado se refere a uma pesquisa qualitativa junto a organizações que executem GPP (através de estudo de casos múltiplos) para ratificar e/ou retificar os fatores organizacionais encontrados na literatura. Posteriormente, uma pesquisa quantitativa (em um formato de Survey) poderá determinar o grau de influência de cada fator organizacional na GPP.

\section{REFERÊNCIAS}

Archer, N.P., \& Ghasemzadeh, F. (1999). An integrated framework for project portfólio selection. International Journal of Project Management, Reino Unido, Vol. 17, nro. 4, p. 207-216.

Artto, K. A., \& Dietrich, P. H. (2007). Strategic business management through multiple projects. New Jersey: John Wiley \& Sons.

Barros, L. A., \& Mello, C. H. P. (2009). Análise de critérios de sucesso para a gestão de portfólio de projetos em uma multinacional da área química. In: XIV Simpósio de Administração da Produção, Logística e Operações Internacionais (SIMPOI), São Paulo.

Blomquist, T., \& Muller, R. (2006). Practices, roles and responsibilities of middle managers in program and portfólio management. Estados Unidos: Project Management Journal, Vol. 37, Nro. 1, p. 52-66.

Carneiro, K. D. A., \& Martens, C. D. P. (2012). Análilse da maturidade em gestão de portfólio de projetos: o caso de instituição financeira de pequeno porte. Revista de Gestão e Projetos - GeP: São Paulo, Vol. 3, nro. 1, p. 252-279, janeiro/junho.

Christiansen, J. K; \& Varnes, C. (2008). From models to practice: decision making at portfólio meetings. International Journal of Quality \& Reliability Management, Vol. 25, Nro. 1, p. 87-101.

Cleland, D. I., \& Ireland, L. R. (2002). Gerência de projetos. Rio de Janeiro: Reichmann \& Affonso Editores.

Revista de Gestão e Projetos - GeP, São Paulo, v. 4, n. 2, p 01-26, mai./ago. 2013. 
Cooper, R. G., Edgett, S. J., \& Kleinschimidt, E. J. (2000). New problems, new solutions: making portfólio management more effective. Industrial Research Institute, Vol. 43, $n^{\circ} 2$.

Dinsmore, P. C., \& Cabanis-Brewin, J. (2009). Manual de gerenciamento de projetos. Rio de Janeiro: American Management Association (AMA).

Dooley, L., Lupton, G., \& O’Sullivan, D. (2005). Multiple project management: a modern competitive necessity. Journal of Manufacturing Technology Management, Vol. 16, Nro. 5, p. 446-482.

Englund, R. L., \& Graham, R. J. (1999). From experience: linking projects to strategy. Journal of Product Innovation Management. Vol. 16, Issue 1, January, p. 52-64.

Engwall, M., \& Jerbrant, A. (2003). The resource allocation syndrome: the prime challenge of multi-project management? International Journal of Project Management, Vol. 21, p. 403-409.

Fernandes, M. M., Silva, M. B., \& Turrioni, J. B. (2010). Modelo teórico-conceitual para gestão de portfólio de projetos Seis Sigma. Revista de Gestão e Projetos-GeP: São Paulo, Vol. 1, nro. 2, p. 03-25, julho/dezembro.

Guedes, R. M. et al. (2011). Alinhamento do portfólio de projetos à estratégia das organizações: um estudo exploratório quantitativo. In: XVI Simpósio de Administração da Produção, Logística e Operações Internacionais (SIMPOI), São Paulo.

Harrison, F. L. (1992). Advanced project management: a structured approach - third edition. Aldershot (England): Gower House.

Jayme, A. C. W. Z; Perrone, A., Monteiro, O., Torres, T. C. R., \& Eichmann, V. (2006). Gestão de portfólio de projetos - Qual é o principal fator crítico para a gestão de portfólio de projetos no setor público e privado. 92 p. Monografia (Pós-graduação em Gerência de Projetos), Fundação Getulio Vargas, Curitiba, PR.

Jeffery, M., \& Leliveld, I.. (2004). Best practices in IT portfólio management. MIT Sloan Management Review, Boston.

Kerzner, H. (2006). Gestão de projetos - As melhores práticas - $2^{a}$. edição. Porto Alegre: Bookman.

Killen, C. P., Hunt, R. A., \& Kleinschmidt, E. J. (2008). Project portfólio management for product innovation. International Journal of Quality \& Reliability Management, Vol. 25, Nro. 1, p. 2438.

Revista de Gestão e Projetos - GeP, São Paulo, v. 4, n. 2, p 01-26, mai./ago. 2013. 
Markowitz, Harry M. (1959). Portfólio selection. Cowles Foundation for Research in Economics at Yale University.

Mariano, A. D. (2008). Gerenciamento de portfólio de projetos: fatores críticos de sucesso e impactos sobre os resultados organizacionais. 109 p. Dissertação (Mestrado em Administração), Faculdade de Economia, Administração e Contabilidade, Universidade de São Paulo.

Martin, C. C. (1976). Project management: how to make it work. New York: AMACOM.

Martinsuo, M., \& Lehtonen, P. (2007). Role of single-project management in achieving portfólio management efficiency. International Journal of Project Management, Vol. 25, p. 56-65.

McFarlan, F. W., McKenney, J. L., \& Pyburn, P. (1983). The information archipelago: plotting a course. Boston: Harvard Business Review.

Meredith, J. R., \& Mantel, S. J., Jr. (1985). Project management: a managerial approach. Estados Unidos da América: John Wiley \& Sons.

Moeckel, A., \& Forcellini, F. A. (2009). Qualidade da informação na gestão de portfólio durante o planejamento estratégico de produtos. Revista Innovare, 8a. Edição, julho-dezembro.

Pennypacker, J. S. (2005). PM Solutions' Project Portfólio Management Maturity Model. Center for Business Practices, Havertwon (Pennsylvania/USA).

Pinto, J. K., \& Slevin, D. P. (1988). Critical success factors in project implementation. Estados Unidos da América: John Wiley \& Sons.

Project Management Institute(PMI) (2008a). A guide to the project management body of knowledge (PMBOK Guide) - fourth edition. Pennsylvania: PMI.

(2008b). Standard for portfólio management. Estados Unidos da América: PMI Bookstore.

Rabechini, R., Jr. Maximiano, A. C. A., \& Martins, V. A. (2005). A adoção do gerenciamento de portfólio como uma alternativa gerencial: o caso de uma empresa prestadora de serviço de interconexão eletrônica. Revista Produção: São Paulo, Vol. 15, nro. 3, p. 416-433, setembro/dezembro.

Wheelwright, S. C., \& Clark, K. B. (1993). Managing new product and process development. The Free Press, Estados Unidos da América.

Revista de Gestão e Projetos - GeP, São Paulo, v. 4, n. 2, p 01-26, mai./ago. 2013. 
Data do recebimento do artigo: 22/04/2013

Data do aceite de publicação: 30/06/2013

Revista de Gestão e Projetos - GeP, São Paulo, v. 4, n. 2, p 01-26, mai./ago. 2013. 